\title{
Intranasal Remifentanil as an Adjunct to Oral Midazolam Sedation in Pediatric Dental Patients
}

\author{
Kundra A*, Heard C, Gardner T, Wanamaker C and Ciambella C \\ Englewood Hospital, USA
}

Submission: February 17, 2017; Published: August 29, 2017

*Corresponding author: Amita Kundra, Englewood Hospital in Englewood, NJ, USA, Email: amita.kundra@gmail.com

\begin{abstract}
Purpose: Oral midazolam (MID) sedation is often used for pediatric dental procedures, however the quality of procedural sedation is variable and maybe inadequate for successful procedure completion. Intranasal (IN) sedative administration can be a useful adjunct as it has a more rapid onset and can be repeated as needed. MID can also be given IN however it burns and often results in crying. Routinely we use adjunct IN sufentanil, but due to a prolonged drug shortage and unavailability ( $>1$ year) we decided to assess the efficacy and safety of IN remifentanil (REMI), an ultra short acting synthetic opiate. There are only a few papers on IN REMI use. One report of 150 children given IN REMI as an adjunct to intubation did not find any problems and the kinetics appeared to demonstrate a fast onset of IN REMI and a rapid elimination as expected.

Methods: We performed at retrospective chart and QA database review of this novel sedation technique. Children scheduled for elective moderate dental sedation procedures were given $0.7 \mathrm{mg} / \mathrm{kg}$ oral midazolam. Since the shortage of Sufentanil we started using REMI in June 2012. We gave 2 to 4 doses $(2 \mathrm{mcg} / \mathrm{kg}$ ) of IN REMI (Maximum REMI dose used was $40 \mathrm{mcg}$ ). The first dose was given in the PREAN area 25 minutes after the MID dose. The next dose was given when the child was in the dental chair and monitoring applied in the operatory. Any subsequent doses were given at a minimum of 5 minute intervals at the request of the dentist performing the procedure. All patients were monitored with pulse oximetry, HR and NIBP. The quality of sedation, airway complications and discharge times were assessed as part of our QA process. The IN REMI was prepared each day at a $100 \mathrm{mcg} / \mathrm{ml}$ concentration (in NS) and administered using a MAD atomizer device. The volume for each spray was about $0.3-0.4 \mathrm{ml}$. The right nares were used first and then the alternate nares were used for any repeat dosing.
\end{abstract}

Results: Data was collected on 74 children. The mean age was 5.5 years (Range 2 - 13) and the mean weight was 22.3kg (Range 12-68). The mean MID dose was 12.6.mg, 51\% were female. The median number of dental procedures performed on each child was 3 (range 1-9). The mean total dose of REMI given was $94 \mathrm{mcg}$. The median number of REMI doses given was 3 (range 2-4). The depth of sedation was assessed using the RASS score. The median RASS score at: MID dosing, Entry into the Operatory, During the Procedure, and arrival in the PACU were: $0,-1,-1$, and 1 , respectively. The mean procedure duration was 30 minutes. And the mean discharge time was 50 minutes. The median dental assessment score was 5.0. All procedures were completely successfully. There were 2 airway complications noted. Two patients had a desaturation to 90 , this was treated with supplemental oxygen in 1 child ( 2 REMI doses) and no treatment was required in the other ( 3 REMI doses). There were no episodes of apnea, airway obstruction, or bradycardia.

Conclusion: The REMI appeared to be an effective adjunct to oral MID. Due to its short half life, repeat dosing of the REMI appears necessary to obtain an useful duration of effect. Although we had minimal respiratory side effects, as there is a risk of apnea and rigidity from this potent opiate we decided to titrate the dosing of REMI to the desired effect. The optimal dosage strategy still needs to be determined.

\section{Introduction}

Oral sedatives are often required for children who require dental restoration. Most children are able to receive this in the dental office, often using nitrous oxide with minimal sedation to facilitate the procedure. However, there are children who will not cooperate during the examination process or during the actual dental procedure without sedation [1]. This can be due to young age, behavior issues or non-compliant behavior. As a result, these children are scheduled for oral moderate sedation in the office setting. We routinely use oral midazolam as our

sedation method. Midazolam has a wide safety margin and is effective in about $80 \%$ of the patients [2]. We use a dose of 1 $\mathrm{mg} / \mathrm{kg}$ up to a maximum of $20 \mathrm{mg}$, wait 30 minutes where the child is monitored in the preoperative area before going into the operating room.

In 2012 and 2013, there was a national drug shortage affecting sedatives and other anesthetic agents. This resulted in several months of very short supply of oral midazolam. With a waiting list of over 3 months, cancelling these childrens' 
procedures would result in added burden for their families and them. We decided to evaluate an alternative sedation regimen that would conserve oral midazolam use. In the past, we have used intranasal sufentanil as an adjunct to oral midazolam. However during this drug shortage period, the only parenteral opiate that was available was remifentanil. Remifentanil is a newer synthetic opiate that has a rapid onset and a very short half-life of 8 minutes $[3,4]$.

In addition, remifentanil has a very short and stable contextsensitive half time. As a result, it has been used intravenously in pediatric patients including critically ill neonates. It has pronounced cardiac stability and is a potent respiratory depressant [5]. It usually administered by infusion and IV bolus use has been also reported but the risks of apnea and muscle rigidity have limited this approach [6,7]. There appears to be very limited experience with using remifentanil intranasally. A paper by Verghese et al. [8] published 2008 in Anesthesia and Analgesia, reported the use of intranasal remifentanil and intubating conditions in a study involving 188 children aged 1 to 7 years. Remifentanil was dosed at $4 \mathrm{mcg} / \mathrm{kg}$ after induction of anesthesia, some patients had blood levels checked for kinetic analysis. Peak plasma levels occurred after 4 minutes and intubating conditions were superior in the remifentanil group compared to the placebo. There were no side effects or complications noted secondary to the remifentanil [8]. We initiated a quality assessment $(\mathrm{QA})$ review process to evaluate this new adjunct sedation medication. We were interested in the efficacy, side effects and the effective dose. The aim of this report is to describe our experience with intranasal remifentanil as an adjunct to oral midazolam sedation.

\section{Methods}

For the QA process, a nurse not involved in the clinical care of the child collected data prospectively. Data collection included patient demographics, drug dosing and administration times, sedation quality, number of dental procedures and complications such as desaturation, bradycardia, muscle rigidity or tachyphylaxis.

After this QA process was completed and the results discussed in our department we obtained IRB approval for the publication of this data from a retrospective review of the QA database. The sedation method included $0.7 \mathrm{mg} / \mathrm{kg}$ oral midazolam (maximum dose $14 \mathrm{mg}$ ) with the routine ASA monitoring. The first dose of the remifentanil was given in the preoperative area with the parents present. Remifentanil solution does not cause pain on administration [9]. Five minutes later the child was taken to the operating room and monitored with pulse oximetry, heart rate and non-invasive blood pressure. Oxygen was delivered via nasal cannula. Naloxone and flumazenil were immediately available for intranasal administration if required.

The concentration, dose of remifentanil and the number of administrations evolved as we gathered more experience with the technique. Initially we used $50 \mathrm{mcg} / \mathrm{ml}$ giving 1 or 2 doses of $1 \mathrm{mcg} / \mathrm{kg}$ and eventually we used $100 \mathrm{mcg} / \mathrm{ml}, 2 \mathrm{mcg} / \mathrm{kg}$ doseup to 4 doses as required. The maximum dose used was $60 \mathrm{mcg}$. The $1 \mathrm{mg}$ vial of remifentanil powder was dissolved in saline to produce the desired concentration. Then $0.6 \mathrm{ml}$ of remifentanil was then drawn up into $1 \mathrm{ml}$ luer lock syringes for use during the day, all unused remifentanil was wasted and documented after the day was complete. All doses were weight based and drawn into luer lock syringes. All remifentanil was administered using a disposable mucosal atomization device (MAD®, LMANA). This is a device that attaches to a luer lock syringe and deposits a fine spray during administration, ensuring an even spread of the medication onto the mucosal surface of the nose. Further doses were given as deemed indicated by the operating dentist.

Sedation quality was assessed using the Richmond Agitation Sedation Score (RASS). The QA observer assessed this at various times during the procedure. Also the dentist and the observer independently rated the overall quality of the sedation on a visual analogue scale (VAS), 1 - 10.

\section{Results}

Table 1: Patient Demographics.

\begin{tabular}{|c|c|c|c|c|}
\hline & $\begin{array}{c}\text { Age } \\
\text { (years) }\end{array}$ & $\begin{array}{c}\text { Gender (\% } \\
\text { female) }\end{array}$ & Weight (kg) & $\begin{array}{c}\text { Number of } \\
\text { Procedures }\end{array}$ \\
\hline $\begin{array}{c}\text { Mean / } \\
\text { Median }\end{array}$ & 5.5 & 47.3 & 22.3 & 3 \\
\hline SD / - & 2.7 & - & 8.6 & - \\
\hline Minimum & 2 & - & 12 & 1 \\
\hline Maximum & 13 & - & 68 & 9 \\
\hline
\end{tabular}

Table 2: Sedation Doses.

\begin{tabular}{|c|c|c|c|c|c|c|}
\hline & $\begin{array}{c}\text { REMI } \\
\text { Dose } \\
\text { (mcg) }\end{array}$ & $\begin{array}{c}\text { REMI } \\
\text { Total } \\
\text { (mcg) }\end{array}$ & $\begin{array}{c}\text { REMI } \\
\text { Total } \\
\text { (mcg/ } \\
\mathbf{k g} \text { ) }\end{array}$ & $\begin{array}{c}\text { Number } \\
\text { REMI } \\
\text { Doses }\end{array}$ & $\begin{array}{c}\text { MID } \\
\text { Dose } \\
\text { (mg) }\end{array}$ & $\begin{array}{c}\text { MID } \\
\text { Dose } \\
\text { (mg/ } \\
\text { kg) }\end{array}$ \\
\hline $\begin{array}{c}\text { Mean / } \\
\text { Median }\end{array}$ & 34 & 94 & 1.60 & 3 & 12.6 & 0.61 \\
\hline SD / - & 10 & 44 & 0.47 & - & 1.6 & 0.12 \\
\hline Minimum & 15 & 15 & 0.52 & 1 & 8.00 & 0.21 \\
\hline Maximum & 60 & 240 & 2.22 & 4 & 14.00 & 0.75 \\
\hline
\end{tabular}

REMI: Remifentanil

MID: Midazolam

The database review yielded data on 74 patients who received oral midazolam and intranasal remifentanil. Patient demographics are shown in Table 1 . The mean patient age was 5.5 years. Each patient had a median of 3 teeth procedures performed during the sedation. The drug doses are shown in Table 2. There was a significant variation in the dosing of remifentanil as we changed our dosing schedule several times. The midazolam dose was within the dosing parameters of this technique. Remifentanil dosing was divided into three different schedules (Table 3). The initial evaluation (low, $n=11$ ), the 


\section{Journal of Anesthesia \& Intensive Care Medicine}

second dosing schedule (intermediate, $n=10$ ) and the final evaluation (high, $n=53$ ). Dose escalation occurred with both an increase dose as well as number of remifentanil intranasal

\begin{tabular}{|c|c|c|c|c|c|}
\hline & Dosing Schedule & $\begin{array}{c}\text { CONC. REMI (mcg/ } \\
\text { ml) }\end{array}$ & $\begin{array}{c}\text { REMI DOSE (mcg/ } \\
\text { kg) }\end{array}$ & $\begin{array}{c}\text { TOTAL REMI (mcg/ } \\
\text { kg) }\end{array}$ & $\begin{array}{c}\text { Number of Doses } \\
\text { (median) }\end{array}$ \\
\hline Low(n=11) & 1 to 2 & 50 & 0.96 & 1.86 & 2 \\
\hline Intermediate (n=10) & 2 to 3 & 50 & 1.07 & 2.34 & 2 \\
\hline High (n=53) & 2 to 4 & 100 & 1.81 & 5.08 & 3 \\
\hline
\end{tabular}

REMI: Remifentanil

Table 4: Mean Procedure Times (minutes).

\begin{tabular}{|c|c|c|c|c|c|c|}
\hline & MID to First REMI & Procedure & Discharge & REMI 1 to REMI 2 & REMI 2 to REMI 3 & REMI 3 to REMI 4 \\
\hline All & 23 & 30 & 50 & 9 & 9 & - \\
\hline Low & 22 & 28 & 63 & 8 & 17 & - \\
\hline Intermediate & 21 & 30 & 61 & 9 & 9 & - \\
\hline High & 24 & 30 & 46 & 5 & 5 \\
\hline
\end{tabular}

\section{MID: Midazolam}

REMI: Remifentanil

REMI1 to REMI2: time interval between first and second remifentanil dose.

Procedure times are shown in Table 4. The mean procedure time was 30 minutes and discharge time of 55 minutes. We compared this to data from our sedation QA database for full dose oral midazolam, (data taken from the six months period prior to remifentanil use, $n=83$ ). The full dose midazolam had a mean discharge time of 70 minutes, this is significantly longer $(\mathrm{p}<0.01)$ than the IN remifentanil patients. The quality of the sedation appeared to be significantly better with the high dose group of patients (Table 5). The RASS scores between the

three groups were similar for oral dosing of midazolam, initial IN remifentanil dose and entering the operator. The high dose group had significantly better RASS for the procedure $(\mathrm{p}=0.004)$, compared to the other dosing schedules. The benefit was also noted initially in the recovery room $(p=0.02)$. The dentist's VAS assessment (Table 6) was significantly better for the high dose group ( $\mathrm{p}=0.004)$, as was the observer's VAS assessment $(\mathrm{p}=0.001)$.

Table 5: Richmond Agitation Sedation Score, Comparing different Remifentanil Dosing.

\begin{tabular}{|c|c|c|c|c|c|c|c|c|}
\hline & MID & FIRST REMI & Enter & Procedure & PACU & REMI2 & REMI3 & REMI4 \\
\hline Low & 0 & -1 & -1 & 2 & 0 & -1 & 2 \\
\hline Intermediate & 0 & -1 & -1 & 2 & 0 & -1 & 2 \\
\hline High & 0 & -1 & -2 & -1 & -1 & -1 & -1 & 1 \\
\hline
\end{tabular}

MID: Midazolam administration

FIRST REMI: First remifentanil dose given

REMI2: Second remifentanil dose give

Table 6: Dentist and Observer Assessment.

\begin{tabular}{|c|c|c|}
\hline & Dentist Assess & Observer Assess \\
\hline Low & 4 & 5 \\
\hline Intermediate & 4 & 5 \\
\hline High & 8 & 9 \\
\hline
\end{tabular}


Table 7: Complications and Comments.

\begin{tabular}{|c|c|}
\hline Case & Comments \\
\hline 5 & Next dose given before wore off with good effect \\
\hline 9 & $\begin{array}{c}\text { Sat 92\%, asked to breathe deeply corrected no } \\
\text { intervention required }\end{array}$ \\
\hline 25 & Effect lasted 12 minutes \\
\hline 28 & Didn't re-dose early enough \\
\hline 29 & Sat 90\%, spontaneously resolved, no intervention \\
\hline 33 & Effect lasted 10 minutes \\
\hline 36 & Didn't re-dose early enough \\
\hline 38 & Didn't re-dose early enough \\
\hline 54 & Responded well to REMI, very uncooperative on \\
entry to operatory
\end{tabular}

Two patients experienced desaturation episodes (Table 7). One in the low dose group (Patient 9) and one in the high dose group (patient 25). There were no cardiac complications. There were no complaints of nausea or vomiting, chest rigidity or tachyphylaxis. Comments noted during the QA review included several concerning the short duration of effect (10-12 minutes) from the IN remifentanil and the need to re-dose before the effect had worn off. In fact, the next dose was most effective if given before the child became uncooperative.

Table 8: Pharmacokinetic Parameters for Simulation.

\begin{tabular}{|l|c|}
\hline Weight (kg) & 20 \\
\hline Dose (mcg/kg) & 2 \\
\hline Dose (mcg) & 40.0 \\
\hline F (Bio-availability) & 0.25 \\
\hline Ka (1/h, Absorb co-efficient) & 30 \\
\hline Vd (L) & 7.8 \\
\hline CL (L/h) & 40 \\
\hline T max (minutes) & 4.3 \\
\hline Ke (1/h elimination constant) & 5.1 \\
\hline Half - Life (minutes) & 8.1 \\
\hline
\end{tabular}

A pharmacokinetic simulation plot (Excel spreadsheet, based upon published kinetic data, Table 8) shown in Figure 1. Demonstrates the changes in remifentanil blood levels when administering 4 doses of intranasal remifentanil in a manner as we have reported. The rapid onset of the IN remifentanil allows a quick increase in the blood level, which also falls quickly due to the short half-life. The blood level increased with each IN administration, indicating that a steady state had not yet been achieved.

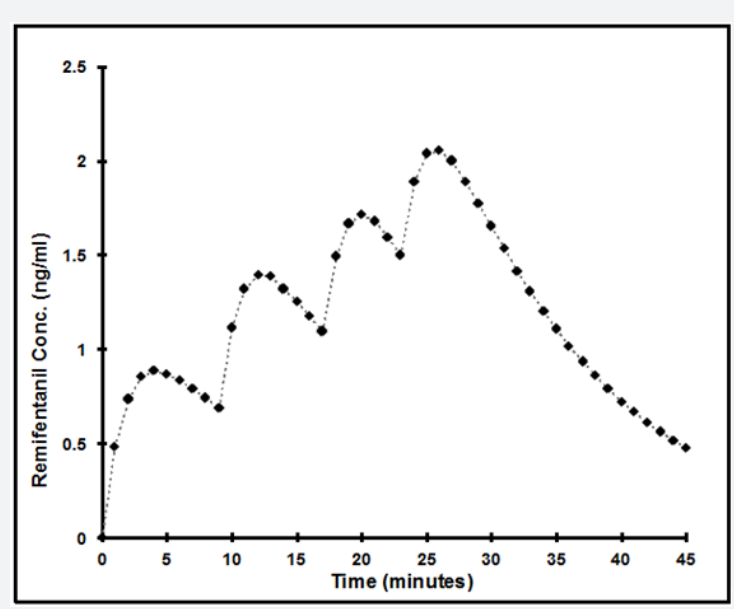

Figure 1: Pharmacokinetic Simulation for 4 Intranasal Doses of Remifentanil.

Extrapolated from published data (ref 8). $20 \mathrm{~kg}$ Child, four 40 mcg IN doses given at the dosing schedule from this report. Pharmacokinetic parameters shown in Table 8.

\section{Discussion}

In light of recent drug shortages, this QA report and subsequent data analysis reviews the off-label use of intranasal remifentanil for moderate sedation in the pediatric population. In this study, the higher dose group of $100 \mathrm{mcg} / \mathrm{ml}$ with $2 \mathrm{mcg} /$ $\mathrm{kg}$ dose, up to 4 doses provided adequate sedation to these patients with minimal side effects. In the high dose group the depth of sedation was consistent with moderate sedation (RASS: -1 or -2 ) and the procedures were all completed satisfactorily.

Among all the patients receiving this treatment, only two episodes of desaturation occurred to $90 \%$ with no intervention required. In addition, no episodes of tachyphylaxis, nausea or chest rigidity were observed. Intranasal adjunct medication is an attractive option due to the ability to give multiple doses without requiring the cooperation of the patient [10-12]. Intranasal medications often have a faster onset, in this case remifentanil peak effect is within 5 minutes, this facilitates a safe titration to effect method, as the peak effect can be seen before the next dose is given. However the intranasal approach reduces the risk of apnea and rigidity that could be seen with bolus remifentanil, due to this onset delay [8]. The remifentanil must be diluted into an appropriate concentration, the optimal volume for an intranasal mediation is less than $0.5 \mathrm{ml}$, larger volumes result in a greater degree of unpredictability due to delayed swallowed medication effect, sensitive to the effects of first pass metabolism. The volume we used for all cases was a maximum of $0.6 \mathrm{ml}$, irrespective of the dose given.

Whenever a drug must be mixed, this increases the risk for error, also a small volume error of $0.1 \mathrm{ml}$ could result in a dose error of $25 \%$ [13]. When using potent opiates as part of a sedation method, extra care must be taken with the preparation 
and administration. A simple reminder, the volume should never be greater than $0.6 \mathrm{ml}$ could help limit the risk of a severe overdose.

The use of the MAD improves the distribution of intranasal administered medications. There is a small dead space volume $(0.05 \mathrm{ml})$ that should not be a problem unless very small volumes are being used [14].

The pharmacokinetic simulation demonstrates however, that this dosing regimen can still result in remifentanil levels that could cause apnea. Higher blood levels of remifentanil in a patient who has also received benzodiazepine further increases this potential risk. The study by Verghese et al. [8] demonstrated no problems using $4 \mathrm{mcg} / \mathrm{kg}$ as a single dose, however in these patients apnea was not a problem and actually desired, to facilitate the intubation process, this was not the endpoint in our analysis. We used a step-wise dosing schedule to evaluate the effects of remifentanil, increasing the individual dose as well as the number of doses in a structured manner to ensure that safe sedation was given. The high dose remifentanil schedule appears to be a safe and effective dosing method, using 3-4 doses with at least 5 minutes between each subsequent dose.

Remifentanil is one of the more higher cost sedation agents available at present. A $1 \mathrm{mg}$ vial from our supplier costs about $\$ 70$. If this can be used between multiple patients then the cost may be acceptable. This report has several limitations. It is a retrospective review of a QA database. There was also no randomization of patients nor blinding of the observer or dentists. The patients were a convenience sample that presented to the clinic on days we were able to do the QA analysis and as such are reflective of our sedation population. However our population may be significantly different than those in other university or private offices. Therefore, a single center study may not be generalizable. This is the first report of the use of intranasal remifentanil as a sedative in pediatric patients. There may be several other opportunities for such a rapid acting, titratable, painless non-IV based parenteral sedation method such as patients requiring short painful procedures, patients with chronic pain for break-through management or as an anesthesia premedication.

\section{Conclusion}

As a result of the national shortage of drug supply, this review explored unique modalities for administration of remifentanil in a pediatric dental population. The intranasal remifentanil appeared safe and effective, however it was labor intensive due to the multiple dosing iteration schedule we utilized for safety reasons. Due to the small sample size, and limited demographic, further prospective randomized studies are necessary in both the adult and pediatric populations.

\section{References}

1. Heard CMB, Wanamaker C (2015) Dental Sedation in Children. Curr Anesthesiol Rep 5: 115-124.

2. Heard CMB, Joshi P, Michienzi K, Feldman D, Creighton P (2010) A comparison of 4 different conscious sedation techniques for the pediatric dental patient. Pediatric Anesthesia 20(10): 924-930.

3. Egan TD (1995) Remifentanil pharmacokinetics and pharmaco dynamics. A preliminary appraisal. Clin Pharmacokinet 29(2): 80-94.

4. Ross AK, Davis PJ, Dear Gd GL, Ginsberg B, McGowan FX, et al., (2001) Pharmacokinetics of remifentanil in anesthetized pediatric patients undergoing elective surgery or diagnostic procedures. Anesth Analg 93: 1393-1401.

5. Sammartino M, Garra R, Sbaraglia F, De Riso M, Continolo N (2010) Remifentanil in children. Paediatr Anaesth 20(3): 246-255.

6. Babenco HD, Conard PF, Gross JB (2000) The pharmacodynamic effect of a remifentanil bolus on ventilatory control. Anesthesiology 92(2): 393-398.

7. Sá Rêgo MM, Inagaki Y, White PF (1999) Remifentanil administration during monitored anesthesia care: are intermittent boluses an effective alternative to a continuous infusion? Anesth Analg 88(3): 518-522.

8. Verghese ST, Hannallah RS, Brennan M, Yarvitz JL, Hummer KA, et al. (2008) The effect of intranasal administration of remifentanil on intubating conditions and airway response after sevoflurane induction of anesthesia in children. Anesth Analg 107(4): 1176-1181.

9. Antonio C, Zurek J, Creighton P, Johnson K, Heard CMB (2011) Reducing the Pain of Intranasal Drug Administration. Pediatr Dent 33(5): 415419.

10. Hitt JM, Corcoran T, Michienzi K, Creighton P, Heard C (2016) An Evaluation of Intranasal Sufentanil and Dexmedetomidine for Pediatric Dental Sedation. Pharmaceutics 6(1): 175-184.

11. Karl HW, Keifer AT, Rosenberger JL, Larach MG, Ruffle JM (1992) Comparison of the safety and efficacy of intranasal midazolam or sufentanil for preinduction of anesthesia in pediatric patients. Anesthesiology 76(2): 209-215.

12. Borland M, Jacobs I, King B, O’Brien D (2007) A randomized controlled trial comparing intranasal fentanyl to intravenous morphine for managing acute pain in children in the emergency department. Ann Emerg Med 49(3): 335-340.

13. Merry AF, Anderson BJ (2011) Medication errors--new approaches to prevention. Paediatr Anaesth 21(7): 743-753.

14. Pandey RK, Bahetwar SK, Saksena AK, Chandra G (2011) A comparative evaluation of drops versus atomized administration of intranasal ketamine for the procedural sedation of young uncooperative pediatric dental patients: a prospective crossover trial. J ClinPediatr Dent 36(1): 79-84. 


\section{Your next submission with Juniper Publishers} will reach you the below assets

- Quality Editorial service

- Swift Peer Review

- Reprints availability

- E-prints Service

- Manuscript Podcast for convenient understanding

- Global attainment for your research

- Manuscript accessibility in different formats ( Pdf, E-pub, Full Text, Audio)

- Unceasing customer service

Track the below URL for one-step submission https://juniperpublishers.com/online-submission.php 